\title{
Article
}

\section{Partner abuse and its association with emotional distress: A study exploring LGBTI relationships}

Ireland, Jane Louise, Birch, Philip, Kolstee, Johann and Alison, Ritchie

Available at http://clok.uclan.ac.uk/18470/

Ireland, Jane Louise ORCID: 0000-0002-5117-5930, Birch, Philip, Kolstee, Johann and Alison, Ritchie (2017) Partner abuse and its association with emotional distress: A study exploring LGBTI relationships. International Journal of Law and Psychiatry . ISSN 0160-2527

It is advisable to refer to the publisher's version if you intend to cite from the work. http://dx.doi.org/10.1016/j.jijp.2017.06.005

For more information about UCLan's research in this area go to http://www.uclan.ac.uk/researchgroups/ and search for <name of research Group>.

For information about Research generally at UCLan please go to http://www.uclan.ac.uk/research/

All outputs in CLoK are protected by Intellectual Property Rights law, including Copyright law. Copyright, IPR and Moral Rights for the works on this site are retained by the individual authors and/or other copyright owners. Terms and conditions for use of this material are defined in the policies page.

\section{CLoK}

Central Lancashire online Knowledge www.clok.uclan.ac.uk

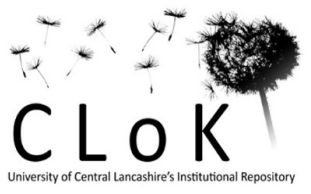


RUNNING HEAD: PARTNER ABUSE IN LGBTI COMMUNITIES

Partner abuse and its association with emotional distress: A study exploring LGBTI relationships

Jane L. Ireland*,

Ashworth Research Centre, Mersey Care NHS Trust and University of Central Lancashire, UK

Philip Birch, University of Western Sydney, Australia

Johann Kolstee

Manager Research Engagement, ACON, Australia

Alison Ritchie,

Ashworth Research Centre, Mersey Care NHS Trust and University of Central Lancashire, UK

*Corresponding author Professor Jane L. Ireland, JLIreland1@uclan.ac.uk; Ashworth Research Centre, Mersey Care NHS Trust and University of Central Lancashire, UK 


\begin{abstract}
This study examines partner abuse in LBGTI relationships, with focus on the associations with emotional distress and protective factors. Two hundred and eighty-seven participants took part. Partner abuse (victimisation) comprised three factors; conflict orientated aggression; hostile ignorance and control of communication; and social control and possessiveness (including threats to possessions). Perpetration factors were similar. Significant differences across sexuality or gender were limited to the perpetration of abuse relating to suspicion and possessiveness, where men were more likely to report this than the other gender groups, and women were less likely to report this. Of those reporting abuse in their current relationship, over half reported experiencing abuse in a primary relationship previously, with 60 per cent reporting exposure to abuse as a child. Partner abuse in their current relationship predicted current levels of increased emotional distress, with reduced satisfaction with the current relationship having an indirect impact on this association. Resilience traits were not a predictor or mediator. The results demonstrate the similarity in abuse across LGB communities despite the diversity of genders, sexualities and experiences within these groups. The results are discussed with regards to directions for future research and implications for practice.
\end{abstract}

Keywords; LBGTI; Partner Abuse; Emotional Distress; MMEA; PCL-C

Research into Intimate Partner Violence (IPV), often also captured within the term Domestic and Family Violence (DFV), represents one of the most frequently studied forms of interpersonal violence (Hamel, 2006; Hamel \& Nicholls, 2006). Despite this, research has focused on heterosexual relationships with limited research addressing Lesbian, Gay, 
Bisexual, Transgender and Intersex (LBGTI) relationships (Baker, Buick, Kim, Moniz \& Nava, 2013; Cannon \& Buttell, 2015; Dececco, Letellier \& Island, 2013; Edwards, Sylaska \& Neal, 2015; Turell, Herrmann, Hollander \& Galletly, 2012). For example, in their review, Edwards et al (2015) noted that of around 14,200 studies published in the field of IPV/DFV in the past 15 years, only approximately 3\% focused specifically on the LGB community, with a near neglect of transgender and intersex individuals (Courvant \& Cook-Daniels, 2012; Papazian, \& Ball, 2016).

Of the limited research conducted with LGBTI communities, it has been concluded that IPV/DFV occurs just as often as, if not more, than in heterosexual relationships (Black et al, 2011). However, the extent of such violence in LGBTI communities varies greatly, ranging from 1\% (Turell, 2000) to more than 97\% (Hequembourg, Parks \& Vetter, 2008). Specifically focusing on male victims, Nowinski \& Bowen (2012) reported that homosexual male victimisation ranged between $1.8 \%$ and $93.7 \%$. However, they also recognised the methodological weaknesses inherent in measuring such abuse, with such concerns reflected in other research that focused on LGB populations (e.g. Bartholomew, Regan, Oram \& White, 2008). Such methodological issues include small sample sizes, a reliance on selfreport methods and indicators for sexuality and gender not being properly worded. These methodological difficulties are not unique to LBGTI research and are noted more broadly in the partner violence literature where a focus on self-selecting samples and specialised samples has also been criticised (Capaldi, Knoble, Shortt \& Kim et al, 2012).

A further criticism of LGBTI IPV/DFV research is how it has focused on the more extreme forms of intimate partner violence, such as sexual abuse (e.g. Turell, 2000), or on direct abuse, involving both physical and psychological abuse (Hequembourg et al, 2008). There remains limited attention paid to more subtle forms of aggression, including the full range of emotional abuses that can occur (Outlaw, 2009). Research into emotional abuse is 
in its infancy compared to other forms of aggression (Murphy \& Hoover, 1999; O’Leary \& Maiuro, 2001; Outlaw, 2009, Ireland \& Birch, 2013). This is particularly the case for the IPV/DFV literature whereas in other areas of research, such as bullying, the concept of subtle and more indirect forms of aggression has been recognised and researched for many years (Björkqvist, Lagerspetz \& Kaukiainen, 1992; Ireland, 2011).

Regarding the specific nature of partner violence in LGBTI relationships, there is some consensus that verbal abuse is the most commonly reported; Kelly and Warshafsky (1997), for example, found that 95\% of their gay and lesbian sample reported using verbally abusive tactics with their partners. Houston and McKirnan (2007) also found verbal abuse to be the most common reported (20.6\%) in their sample of gay and bisexual men. This was closely followed by physical violence (19.2\%) and unwanted sexual activity (18.5\%) (Houston \& McKirnan, 2007). Some research has, however, uncovered the presence of emotional abuse in LGBTI relationships. Turell (2000), for example, reported that the 83\% of gay men reported experiencing emotional abuse in their relationships. Multiple forms of abuse also commonly occur; $54 \%$ of those who had reported any abuse history, reported experiencing more than one form of abuse from their partner (Houston \& McKirnan, 2007). Regarding comparisons between the LGBTI and heterosexual communities, Black et al (2011) found that $44 \%$ of lesbian and $61 \%$ of bisexual women reported experiences of rape, physical violence and/or stalking by an intimate partner across their lifetime, with $35 \%$ of heterosexual women reporting the same. Twenty six per cent of gay men and $37 \%$ of bisexual men reported experiencing these forms of partner violence compared to $29 \%$ of heterosexual males (Black et al, 2011). The Another Closet organisation in New South Wales recognises the problem of violence in LBGTIQ relationships, noting how the prevalence rates and impacts are similar to non-LBGTIQ populations, and focusing on supporting those involved in such relationships (Another Closet, 2014). The It Stops Here 
New South Wales Government Domestic and Family Violence Policy, launched in 2014, further focused on the violence that occurred within domestic situations in LGBTIQ relationships, recognising the similarities in prevalence and nature between LGBTIQ and non-LGBTIQ relationships and also the vulnerability of the LGBTIQ population in terms of difficulties in seeking help from mainstream domestic violence agencies.

Existing literature also tends to focus on the risk factors associated with IPV/DFV as opposed to protective factors (e.g. Andraski, Valentine \& Pantalone, 2013; Balsam \& Szymanski, 2005; Bartholomew, Regan, Oram \& White, 2008; Craft \& Serovich, 2005). Risk factors examined most often include mental health (Houston \& McKirnan, 2007), in which increased levels of anxiety and depression have been associated with victimisation (Salom, Williams, Najman, \& Alati, 2015). Houston and McKirnan (2007) also found that depression was significantly related to partner violence in men in same-sex relationships, and that abused men were more likely to report depressive symptoms than non-abused men. Negative developmental life experiences, such as child abuse or witnessing parental violence, were also well captured as risk factors in the IPV literature base (O’Keefe, 1997; Fortunata \& Kohn, 2003; Daigneault, Hébert \& McDuff, 2009; Nieves-Rosa, Carballo-Diéguez \& Dolezal, 2000; Rosen, Parmley, Knudson \& Fancher, 2002; Craft \& Serovich, 2005). For example, individuals who witnessed parental partner violence as a child or experience abuse themselves as children have been reported to be more likely to engage in violent behaviours in their adult relationships than those who do not have these childhood experiences (O'Keefe, 1997). Fortunata \& Kohn (2003) found that lesbian perpetrators of partner violence were more likely to have experienced abuse as children than non-perpetrators, with Daigneault et al (2009), Nieves-Rosa et al (2000) and Rosen et al (2002) reporting the same for gay victims than non-victims. This has also been reported for those witnessing parental violence (Craft \& Serovich, 2005). These findings suggest that exposure to, or experiencing abuse as a child, 
can increase the likelihood of becoming a victim or perpetrator in adult relationships for those in the LGBTI community, as recognised in the work of Craft \& Serovich (2005), Bartholomew et al (2008), Houston \& McKirnan (2007) and Landolt \& Dutton (1997). It also demonstrates a need for perpetration to be examined alongside victim potential, since the latter appears to be the main focus of research more broadly (Capaldi et al, 2012).

Protective factors thought to reduce the risk of IPV/DFV are important to consider. They can include resilience traits, strong social support (Gondolf, Fisher, Fisher, \& McPherson, 1988; Carlson, McNutt, Choi \& Rose, 2002; Glass, Koziol-McLain, Campbell \& Block, 2004) and good relationship quality (Cramer, 2003, Testa \& Leonard, 2001). As noted, protective factors have been neglected by the research, compared to risk factors, either in the LGBTI or heterosexual literature. Relationship satisfaction has been of particular interest and is thought to act as a protective factor in terms of partner violence likelihood; if individuals are satisfied with their relationship quality, partner violence is less likely to occur (Cramer, 2003, Testa \& Leonard, 2001). A meta-analysis by Stith, Green, Smith \& Ward (2008) found a significant negative relationship between marital satisfaction and partner violence. However, this did not include studies examining the LGBTI community and was limited to married couples, excluding dating and cohabiting couples. Relationship satisfaction and social support do appear to represent the most commonly considered potential protective factors whereas areas more commonly talked about in the emotional distress literature as important in mediating impacts, such as resilience traits, appear not to have received equal attention (Carlson et al, 2002), and certainly not with regards to the extent to they could buffer against the likely negative impacts of being in a conflictual relationship. However, as noted earlier, the LGBTI community is arguably limited in terms of services they can seek support from, with one potential factor impacting on this representing discrimination, or the 
fear of this, if trying to access mainstream domestic and family violence services (Another Closet, 2014).

The focus on heterosexual relationships has arguably limited the application of effective intervention models or strategies for the LGBTI community (Leventhal \& Lundy, 1999; Turell et al, 2012), as the differences between heterosexual and LGBTI relationships are not accounted for. There is a need to develop further research that focuses on the nature and extent of IPV/DFV in LGBTI relationships and with a focus on examining the full range of aggressive behaviours that can be engaged in by partners, along with the protective and aggravating factors that may be in existence. The current study aims to address these areas using a LGBTI sample selected from LGBTI community networks and not from specialist interventions or support programmes. To address the gaps in the literature, the current study will explore a range of aggressive behaviours that could occur within primary intimate relationships.

The study also extends previous research by examining protective factors (e.g. relationship quality, resilience traits) and aggravating factors (emotional distress) that have potential value in terms of assessment and intervention. The predictions made are exploratory considering the limited research in this area beyond descriptive data. However, the following core predictions are indicated: 1.) There will be a positive association between reported abuse and emotional distress; 2.) Relationship satisfaction will moderate the relationship between partner abuse and emotional distress; and 3.) Resilience traits will moderate the relationship between partner abuse and emotional distress.

$$
\text { Method }
$$

Procedure

Members of LGBTI communities across Australia were invited to complete a number of measures online (using esurveycreator as a provider). The survey was supported and 
promoted by ACON (A New South Wales based health promotion organisation specialising in health support for lesbian, gay, bisexual, transgender and intersex). The survey protocol was reviewed and received ethical approval from the University of Central Lancashire. The survey was preceded by an information sheet with a debrief sheet available when the participant had either ended the study or opted out. All measures were completed anonymously.

Participants

Three hundred and eighty-one participants commenced the online survey, with 287 (75.3\%) completing the abuse measure. The survey ran for a period of six months in 2015. Participants were eligible if they lived in Australia. The average age of participants was 34.8 (SD 11.2). Across the sample, $35.7 \%$ identified as male, $54 \%$ as female, $6.1 \%$ as transgender, $2.9 \%$ as intersex, with $1.3 \%$ preferring not to indicate this. In relation to sexuality, $84.9 \%$ (n $=320)$ identified as lesbian, gay or homosexual, $9 \%(n=34)$ as bisexual and $6.1 \%(n=23)$ as 'other' (e.g. pansexual, asexual). Regarding origin, 4.2\% $(n=16)$ reported being aboriginal, 0.5\% $(\mathrm{n}=2)$ Torres Strait Islander and 95.3\% $(\mathrm{n}=361)$ as neither. Almost 70\% reported being Anglo Australia and the remainder as 'other'.

\section{Measures}

Participants were invited to complete a range of measures online, preceded by a demographic questionnaire. The specific measures utilised were as follows:

Brief Resilience Scale (Smith et al, 2008) comprising six items examining positive aspects of personality thought relevant to minimising the impact of negative life events on mental health. Examples of items include "I tend to bounce back quickly after hard times" 
and "I usually come through difficult times with little trouble". The reliability of the measure was moderate to good considering it comprised only six items, producing an $\alpha=.66$.

Multidimensional Measure of Emotional Abuse (MMEA: Murphy \& Hoover, 1999) examines the presence and severity of emotional abuse capturing dominance/intimidation, restrictive engulfment, hostile withdrawal and denigration. The measure was extended from its usual 28 items to 44 items to capture a broader range of potential aggression types, namely physical, verbal, sexual, property damage and controlling behaviours. All 44 items were completed with regards to their own behaviour and also that of their partner, focusing on their current primary relationship (defined as a relationship lasting for at least three months). Example of items included "said or implied that the other person was stupid" and "pushed the other person during a conflict or disagreement”. The reliability of the measure was good and is noted later since the factor structure was examined for this sample.

Support seeking and related history questionnaire: Following the MMEA were a series of questions exploring the support sought (if applicable) as a result of the reported partner abuse, experience of abuse in previous primary partnerships and abuse experiences as a child.

Hospital Anxiety and Depression Scale (HAD: Zigmond \& Snaith, 1983). This is a brief measure of anxiety and depression. It asked participants to report how they had been feeling during the last month. It comprises 14 items (seven for anxiety and seven for depression) such as "worrying thoughts go through my mind" and "I have lost interest in my appearance”. The reliability of the measure was good producing an overall $\alpha=.91$, for anxiety $\alpha=.87$ and depression $\alpha=.85$.

Relationship Satisfaction Measure (Hendrick, 1988). This is a general measure of relationship satisfaction, completed in relation to the participant's current primary relationship. It comprises seven items and does not capture aggression but rather the general 
quality of the relationship and emotional connection between partners. Examples of items include "to what extent has your relationship met your original expectations" and "how much do you love your partner”. The reliability was good, producing an overall $\alpha=.75$.

Abbreviated PCL-C (Lang \& Stein, 2005) is a 14-item measure that focuses on the impact of current stressors on emotional health. It is a shortened version of a PTSD (Post Traumatic Stress Disorder) checklist used for community samples although the term stress is used as an alternative to trauma. It focuses on the extent to which an individual has "been bothered" by a symptom in the last month, with examples including "repeated disturbing memories, thoughts, or images of a stressful experience from the past" and "feeling emotionally numb or being unable to have loving feelings for those close to you”. The reliability of the measure was good producing an overall $\alpha=.94$, with an $\alpha$ of .91 for the intrusion items, $\alpha$ of .88 for avoidance, and $\alpha$ of .83 for the hyperarousal items.

\section{Results}

\section{Estimates of reported abuse}

The most frequently reported forms of abuse were; 'Became so angry that they were unable or unwilling to talk to the other person' $(75.7 \%$ perpetration, $\mathrm{n}=218 ; 72.6 \%$ victimisation, $\mathrm{n}=209)$, 'said that someone else would be a better partner' $(60.7 \%$ perpetration, $n=176 ; 58.7 \%$ victimisation, $n=169$ ), 'refused to acknowledge a problem that the other person felt was important' $(52.2 \%$ perpetration, $n=151 ; 54 \%$ victimisation, $n=$ 156), and 'sulked or refused to talk about an issue with them' (51.6\% perpetration, $\mathrm{n}=149$; $51.6 \%$ victimisation, $\mathrm{n}=149^{1}$ ).

Support seeking and prior abuse history

In relation to seeking support for any of the partner victimisation they had been exposed to, $16.8 \%$ indicated that their primary partner had sought help, $49.7 \%$ that they had 
not, $8.7 \%$ that they did not know and $24.8 \%$ indicated it was not applicable. Regarding their own abusive behaviour towards their partner, 34.2\% reported that they had sought help, with $65.8 \%$ that they had not.

The main reported sources of support were family $(100 \%, \mathrm{n}=59)$, professional organisations $(54.6 \%, n=53)$, friends $(23.7 \%, n=23)$, online support groups $(8.2 \%, n=8)$ and police $(3.1 \%, n=3)$. Sixty-five per cent $(n=183)$ reported that they tried to solve their problems without involving others, with 7.9\% $(\mathrm{n}=22)$ noting they had not done this and $28.8 \%(n=75)$ that it was not applicable.

Of those reporting abuse in their current relationship, $54.4 \%$ noted they had experienced abuse in a primary relationship previously, with $89.6 \%$ reported psychological abuse previously, $72.7 \%$ controlling behaviours, $60.3 \%$ verbal, $46.8 \%$ physical, $35.7 \%$ property damage and $22.1 \%$ sexual.

Sixty per cent reported they had experienced similar abusive behaviours as a child; 51.9\% $(n=80)$ reporting psychological, 42.2\% $(n=65)$ verbal, 39\% $(n=60)$ controlling behaviours, 33.1\% $(n=51)$ physical, $22.7 \%(n=35)$ sexual and $15.6 \%(n=24)$ property damage.

A factor analysis of the partner abuse items was completed to determine the abuse factors indicated for further analysis. Principal Axis Factoring (PAF) was used with Direct Oblim chosen as a result of the inter-association between variables. Analyses were completed separately for perpetration and victimisation since each item is rated separately. For both analyses ten items were removed as there was insufficient variance to allow for a factor structure to be determined if they remained (e.g. they were not endorsed or endorsed by one participant). A scree plot and review of the initial pattern matrix indicated a three-factor solution for both perpetration and victimisation. A final solution was indicated for each, with item loadings restricted to .50 and above as the intention was for a factor score to be 
computed (and therefore requiring loadings of .50 and above only to be included). For victimisation, the solution explained $61 \%$ of the variance overall (with six items not loading) and for perpetration it explained $41 \%$. Results are presented in Table 1 including and scale reliabilities.

In relation to victimisation, the items related to aggression occurring during conflict, including threats and fear inducing being (Factor 1: Conflict orientated aggression, including threats and fear inducing behaviours, comprising 11 items); their partner failing to engage with them (Factor 2: Hostile ignorance and control of communication, comprising 7 items); and their partner controlling their social engagement with others (Factor 3: Social control, suspicion and possessiveness, including threats to possessions, 9 items).

In relation to perpetration the item structure was very similar to that for victimisation. Factor 1 reproduced the victimisation factor concerning failure to engage (Factor 1: Hostile ignorance and control of communication, comprising 7 items). Factor 2 virtually reproduced the aggression during conflict factor, although was comprised only of nine instead of eleven items (Factor 2: Conflict orientated aggression, including threats and fear inducing behaviours, comprising 9 items). Factor three was narrower but still focused on suspicious and possessive behaviour (Factor 3: Suspicion and possessiveness, including threats to possessions, 4 items).

Table 2 presents the overall means and across gender and sexuality. Differences were explored using univariate analysis, with a dummy variable created for each level of gender and sexuality. There were no significant differences noted aside from Factor 3 for perpetration (suspicion and possessiveness, including threats to possessions) where men were more likely to report this than the other gender groups $(\mathrm{F}(1,285)=9.40, p<.002)$ and women were less likely to report this than the other gender groups $(\mathrm{F}(1,285)=5.0, p<.02)$. Regressions were also completed across each of the six factors (three victimisation and three 
perpetration). Each level of sexuality and gender were entered as potential predictions to determine if there were any associations. There were no significant predictors (all $\mathrm{F} \geq 1.48$ ). Mental health

In order to examine the association between emotional distress and disclosed abuse experiences, the measures used to examine distress, namely the HADS (Hospital Anxiety and Depression Scale) and the PCL-C (emotional stress) measures were examined as part of a joint factor analysis to ensure that the content of each were empirically distinct since the intention was to explore emotional distress as an outcome variable for disclosed partner abuse and ensuring there was no redundancy in items was important. Inspection of the anti-image correlation matrix indicated evidence of notable association between the emotional distress measures, suggesting overlapping components. Again, Principal Axis Factoring (PAF) was used with Direct Oblim chosen as a result of the inter-association between variables. An initial scree plot indicated three factors. The final solution comprised 21 items as opposed to the original 31. These are presented in Table 3, limited to those loading .50 and above since the intention was to develop factor scores for later analysis.

The three factors were labelled anxiety and hyperarousal (Factor 1, nine items), loss of enjoyment and interest (Factor 2, five items) and intrusion of stressful events into awareness and attempts to avoid the same (Factor 3, seven items). The first two factors combined both the HADS and PCL-C and seemed to capture anxiety (including extreme forms) and depressive content respectively, with the final factor specific to the PCL-C and focused on active avoidance of a stressful event that was intruding into conscious awareness. The next step was to examine the association between these reconstituted variables of emotional distress and abuse experiences, whilst also accounting for the potential mediating role of resilience and current relationship satisfaction.

Mental health and reported exposure to abuse within current primary relationship 
A series of simple mediation analyses were conducted where reported victimisation within the current relationship was associated with emotional distress. This was conducted with attention to overall victimisation and its noted factor components (i.e. exposure to conflict orientated aggression; exposure to hostile ignorance and control of communication; and exposure to social control and possessiveness). In all analyses victimisation represented the criterion variable, with the outcome variables the three factors of emotional distress; anxiety and hyper-arousal; loss of enjoyment and interest; and intrusion of stressful events into awareness and attempts to avoid the same.

The question the mediation analyses sought to answer was whether or not there was an association between disclosed victimisation by a partner and emotional distress, but importantly whether any such noted relationship was mediated by the participant's resilience traits and their reported perception of current relationship satisfaction. All mediation analyses were conducted using Multiple Regression (Ordinary Least Squares: OLS) with the significance of any indirect effect calculated using the Partial Posterior $\mathrm{P}=$ Value (PPPV) method to determine the amount of mediation. Results were as follows.

\section{$\underline{\text { Overall partner victimisation and emotional distress }}$}

There was a significant association between total experiences of partner victimisation and the emotional distress component of anxiety and hyper-arousal, with increased victimisation predicting higher levels of such distress $(\beta=.44, t=7.38, p<.001)$. Victimisation was not associated with resilience ( $\beta=-.05 n s)$ indicating there was no value in considering further mediation analyses using resilience traits. There was a significant partial mediation, however, for current relationship satisfaction; the indirect effect was significant (PPPV: $p$ <.001) indicating that it was a reduced perception of current relationship satisfaction that was contributing to the association between increased victimisation and increased anxiety and hyper-arousal. This finding was repeated for the emotional distress 
factor loss of enjoyment and interest where there was also a significant association with this and increased overall victimisation $(\beta=.42, t=3.67, p<.001)$. These findings were not replicated for the emotional distress component of intrusion of stressful events into awareness and attempts to avoid the same; although increased reports of partner victimisation did predict increased levels of intrusion $(\beta=.42, t=7.07, p<.001)$, there was no association with relationship satisfaction and intrusion $(\beta=-.07 \mathrm{~ns})$. The significant mediation models are presented in Figure 1.

$<$ Insert Figure 1 here $>$

\section{$\underline{\text { Individual components of partner victimisation and emotional distress }}$}

Mediation analyses were conducted, as for overall partner victimisation and emotional distress, but focused instead on the components of victimisation (i.e. conflict orientated aggression; hostile ignorance and control of communication; and social control, suspicion and possessiveness). Again the mediation variables were considered separately for resilience and perceptions of relationship satisfaction. Resilience was not predicted by any of the abuse components (conflict oriented, $\beta=.07 \mathrm{~ns}$; hostile ignorance, $\beta=-.07 \mathrm{~ns}$; social control, $\beta=$ $.05 \mathrm{~ns}$ ) and thus mediation models using this variable were not explored. With regards to the abuse factor conflict orientated aggression, there was a significant association between this and the emotional distress component of anxiety and hyper-arousal, with increased conflict orientated aggression predicting higher levels of such distress $(\beta=.32, t=5.35, p<.001)$. There was a partial mediation, however, for current relationship satisfaction; the indirect effect was significant (PPPV: $p<.001$ ) indicating that it was reduced perception of relationship satisfaction that was contributing to the association between increased conflict orientated abuse and increased anxiety and hyper-arousal. This was also repeated for the 
remaining emotional distress components where conflict orientated aggression predicted higher levels of both loss of enjoyment $(\beta=.29, t=4.99, p<.001)$ and intrusion $(\beta=.34, t=$ 5.83, $p<.001$ ), with decreased perception of relationship satisfaction partially mediating these relationships with a significant indirect effect (PPPV: $p<.001$ for loss of enjoyment and $p$ $<.003$ for intrusion). Figure 2 presents the mediation analyses.

$<$ Insert Figure 2 here $>$

With regards to the abuse factor hostile ignorance and control of communication, there was a significant association between this and all emotional distress components, with increased hostile ignorance aggression predicting higher levels of such distress (anxiety and hyper-arousal; $\beta=.41, t=7.26, p<.001$; loss of enjoyment; $\beta=.35, t=6.05, p<.001$; intrusion; $\beta=.40, t=6.94, p<.001$ ). There was a partial mediation, however, for current relationship satisfaction across all models with the indirect effect significant (PPPV: $p<.001$ and .04 for intrusion), indicating again that it was reduced perception of relationship satisfaction that was contributing to the association between increased hostile ignorance and control of communication and increased emotional distress. Figure 3 presents the mediation analyses.

$<$ Insert Figure 3 here $>$

Finally, in relation to the abuse factor social control, suspicion and possessiveness, there was a significant association between this and all emotional distress components, with such aggression predicting higher levels distress (anxiety and hyper-arousal; $\beta=.38, t=6.33$, $p<.001$; loss of enjoyment; $\beta=.35, t=6.02, p<.001$; intrusion; $\beta=.36, t=6.04, p<.001$ ). 
There was again partial mediation for current relationship satisfaction across all models with the indirect effect significant (PPPV: $p<.001$ and .03 for intrusion). This again indicated that it was reduced perception of relationship satisfaction that was contributing to the association between increased social control, suspicion and possessiveness and increased emotional distress. Figure 4 presents the mediation analyses.

$<$ Insert Figure 4 here $>$

\section{Discussion}

The current study indicates a range of abusive behaviours disclosed in LGBTI relationships, covering both victimisation and perpetration. The types of abuse reported were captured broadly by three factors; conflict orientated aggression (including threats and fear inducing behaviours); hostile ignorance and control of communication; and social control, suspicion and possessiveness including threats to possessions, with the latter also capturing threats to harm a partner's pet(s). The diversity of abuse reported is consistent with previous literature indicating multiple forms of partner violence in LGBTI communities (e.g. Black et al, 2011; Hequembourg et al, 2008; Houston \& McKirnan, 2007), with verbal aggression and emotional abuse reported frequently, a finding also consistent with previous studies (e.g. Houston \& McKirnan, 2007; Turell, 2000). There appeared considerable overlap between verbal aggression and the concept of emotional aggression, with the latter including tactics such as hostile withdrawal. In the IPV/DFV literature hostile withdrawal is captured more commonly as part of the concept of emotional abuse (Murphy \& Hoover, 1999) whereas in the broader aggression literature it seems part of the well-accepted concept of indirect aggression (e.g. Björkvist et al, 1992). Indeed, a number of the items within the 'hostile withdrawal factor' would appear to be in keeping with more indirect aggression (e.g. 
ignoring), where the intent and aggressive nature is not wholly explicit to those observing or becoming aware of such abuse.

The study also demonstrates how abuse tends to focus on that occurring during or after conflict; both the conflict orientated and hostile withdrawal factors captured this in particular. There were also no differences across gender or sexuality in relation to these particular factors, indicating therefore that they were consistently found across the sample. This finding suggests that pro-social conflict resolution and/or harm minimisation is a valuable avenue to consider in terms of intervention since these abuses are occurring within relationships that are currently being sustained. Although there has been a tendency to focus on assisting with the dissolution of abusive relationships and encouraging the same, there is a developing school of thought, certainly in the risk assessment literature, which focuses on accepting that those engaged in abusive relationships may wish to sustain their relationship. The focus instead shifts to harm reduction and relationship quality enhancement involving both partners, with an increasing consideration of what therapeutic interventions are going to be proven effective for them (e.g. Weiss, 2015).

It is, nevertheless, important to capture the different types of abusive behaviours that are characterising a relationship since a different approach and understanding may apply to each. For example, the abuse factor concerning social control, suspicion and possessiveness appeared across both victimisation and perpetration and was consistent with what is classically described in the IPV/DFV literature as controlling behaviours (Hamel \& Nicholls, 2006). The men in the sample also perpetrated it more towards their partners. Although social control, suspicion and possessiveness are likely to be influenced by context (e.g. a trigger for conflict), it is perhaps not so driven by context than by pre-existing individual characteristics such as personality and paranoid/hostile tendencies. This is speculative since the current study did not examine the individual characteristics associating with each factor 
of abuse disclosed but it does suggest an avenue for future research that captures individual differences as well as contextual factors to determine what is aggravating (or mitigating) partner abuse; trying to resolve conflict in relationships would have to account for the different components of partner abuse, the motivation for each, and pre-existing individual factors.

Interestingly, the current study did find that reporting partner abuse predicted current levels of emotional distress, namely anxiety and hyperarousal, loss of enjoyment (depressive symptoms) and intrusion. This supported the prediction that there would be a positive association between reported abuse and emotional distress. This was consistent with previous research (e.g. Houston \& McKirnan, 2007; Salom et al 2015). However, the current study has expanded the concept of emotional distress beyond areas of depression and anxiety, which are more commonly considered, to also capture trauma/stress related symptoms such as hyperarousal and intrusion. The research does not allow for causal assertions to be made between emotional distress and experiencing partner violence in the current primary partnership; although it could be suggested that these current emotional distress symptoms were related to partner violence, it could equally be the case that what is being identified are unresolved trauma/ distress symptoms from earlier abuse experiences. Indeed, the findings indicated that those indicating experience of partner violence reported other abuses, both within prior relationships and also during childhood/adolescence, with over half of those reporting abuse in their current relationship disclosing abuse in a primary relationship previously, with 60 per cent reporting exposure to abuse as a child. The latter is consistent with previous research reporting how negative developmental life experiences as a child have been associated with partner violence experiences, including the witnessing of conflict between parents and exposure to other abuse (e.g. Bartholomew et al, 2008; Craft \& Serovich, 2005; Daigneault et al, 2009; Fortunata \& Kohn, 2003; Landolt \& Dutton, 1997; 
Nieves-Rosa et al, 2000). The question for future research is whether these pre-existing vulnerabilities have worsened current levels of emotional distress or could explain in part or full current emotional distress. Regardless, it would appear that the majority of those reporting partner violence in the current study were presenting with pre-existing vulnerabilities.

The findings in relation to what mediated the relationship between reports of partner violence and current levels of emotional distress were not completely in keeping with the predictions. Resilience traits were not associated with partner violence and thus the prediction that such traits would moderate the relationship between partner abuse and emotional distress could not be supported. It is important to note that previous research has not focussed on resilience as a more stable trait but rather as a combination of more dynamic factors that include relationship satisfaction and good quality social support (Carlson et al, 2002). The current study, however, focused on resilience as a personality trait since this is more in keeping with the wider literature base on marked emotional distress such as trauma; as a trait it was not, however, contributing and it was relationship satisfaction that was instead. Indeed, it was reduced relationship satisfaction with the current relationship that was having a significant indirect impact on the association between current emotional distress and partner violence. This supported the prediction that relationship satisfaction would moderate the relationship between partner abuse and emotional distress, at least indirectly. Absence of relationship satisfaction appears therefore to represent an aggravating feature. This is similar to research in heterosexual married couples (Stith et al, 2008). However, the current study indicates that not only is lower relationship satisfaction associated with increased levels of partner violence, but, it is also indirectly mediating the relationship between such violence and increased emotional distress. 
It is not surprising that increased partner violence would be associated with decreased relationship satisfaction. What is of interest, however, is the question as to why these relationships are continuing if the satisfaction is low. The gains from the relationship are thus unclear and the barriers to ending the relationship then become of interest. This links with the noted finding that partner violence was characterised by abuse occurring in the context of conflict (e.g. during or following arguments/disagreements, as a response to anger etc.), suggesting that some of these relationships are poor in quality and high in conflict where pro-social and effective means of conflict resolution may be absent. Exploring these areas in more detail would be valuable, suggesting that a potential avenue to explore in terms of the management and prevention is again on how to resolve conflict positively. The aim here would be to raise relationship quality as a way of improving emotional distress. It could be further speculated that raised emotional distress is adding to a risk for arguments and conflicts within these relationships and that a core area to consider in terms of intervention is raising the relationship satisfaction as a means of reducing emotional distress and subsequent conflict.

The current research is not, however, without its methodological limitations, with limitations well recognised in this field of study (e.g. Nowinski \& Bowen, 2012; Capaldi et al, 2012). Although some speculation was offered on possible causal relationships between emotional distress, relationship satisfaction and partner violence, there is no means outside of conducting longitudinal research of testing this; they are at most inferred. The current study also sought its sample primarily through contact with a single, yet large, organisation that supports the LGBTI population at a national and international level. The limitations associated with sampling do, nevertheless, require recognition. In addition, although the current study aimed to acquire a broad sample of the LGBTI community there were few transgender, intersex, asexual and pansexual participants. Small numbers do place 
unavoidable restrictions on the group comparisons that can be made. The study also relied on self-report. It was, however, concerned with emotional abuse (amongst other abuses) for which a reliance on self-report is arguably required since the definition of this can be based on the interpretation of the victim and/or perpetrator. Nevertheless, self-report is a recognised limitation and it can lead to under-reporting of specific forms of abuse that have a high risk of intervention by criminal justice agencies (e.g. physical, sexual, property damage).

The current study is, however, valuable in offering some indication of the nature and extent of partner violence in LGBTI communities and provides suggestions on the components of such violence that are perhaps worthy of future exploration. It also highlights an important role for relationship satisfaction and demonstrated the range of emotional distress factors that require consideration when examining the associates of partner violence. Future research could build on the current findings by examining what pre-existing characteristics may be associated with specific components of partner violence and by identifying further aggravating features, such as substance misuse (Salom et al, 2015) or protective factors such as the quality and quantity of pre-existing social support (Gondolf et al, 1988; Capaldi et al, 2012), all of which have been examined extensively in heterosexual samples but not with LGBTI (Glass et al, 2004). The area could also extend to capture promotive factors, a relatively new concept in the risk field that argues for identification not just of those factors that denote high risk of a behaviour (i.e. a risk factor) but also those that denote low risk (i.e. promotive), alongside protective factors (Farrington, Ttofi \& Piquero, 2016). Considering risk, promotive and protective factors in more detail would assist greatly with developing means of preventing and managing the impacts of IPV on all of those involved; merely describing the problem raises awareness but beyond this the impact is limited.

\section{References}


Andrasik, M. P., Valentine, S. E., \& Pantalone, D. W. (2013). Sometimes you just have to have a lot of bitter to make it sweet: Substance abuse and partner abuse in the lives of HIV men who have sex with men. Journal of Gay \& Lesbian Social Services, 25(3), 287-305. http://dx.doi.org/10.1080/10538720.2013.807215

Another Closet (2014: $3^{\text {rd }}$ Edition), LGBTIQ Domestic and Family Violence. LGBTIQ Domestic Violence Interagency. Retrieved from www.anothercloset.com.org

Baker, N. L., Buick, J. D., Kim, S. R., Moniz, S., \& Nava, K. L. (2013). Lessons from examining same-sex intimate partner violence. Sex Roles, 69(3-4), 182-192. doi: 10.1007/s11199-012-0218-3

Balsam, K. F., \& Szymanski, D. M. (2005). Relationship quality and domestic violence in women's same-sex relationships: The role of minority stress. Psychology of Women Quarterly, 29(3), 258-269. doi: 10.1111/j.1471-6402.2005.00220.x

Bartholomew, K., Regan, K. V., Oram, D., \& White, M. A. (2008). Correlates of partner abuse in male same-sex relationships. Violence \& Victims, 23(3), 344-360. doi: 10.1891/0886-6708.23.3.344

Björkqvist, K., Lagerspetz, K. M. J., \& Kaukiainen, A. (1992). Do girls manipulate and boys fight? Developmental trends in regard to direct and indirect aggression. Aggressive Behavior, 18(2), 117-127. doi: 10.1002/1098-2337(1992)18:2<117::AIDAB2480180205>3.0.CO;2-3

Black, M.C., Basile, K.C., Breiding, M.J., Smith, S.G., Walters, M.L., Merrick, M.T., Chen, J., \& Stevens, M.R. (2011). The National Intimate Partner and Sexual Violence Survey (NISVS): 2010 Summary Report. Atlanta, GA: National Center for Injury Prevention and Control, Centers for Disease Control and Prevention. Retrieved from http://www.cdc.gov/ViolencePrevention/pdf/NISVS_Report2010-a.pdf

Cannon, C., \& Buttell, F. (2015). Illusion of inclusion: The failure of the gender paradigm to 
account for intimate partner violence in LGBT relationships. Partner Abuse, 6(1), 6577. doi: https://doi.org/10.1891/1946-6560.6.1.65

Capaldi, D. M., Knoble, N. B., Shortt, J. W., \& Kim, H. K. (2012). A systematic review of risk factors for intimate partner violence. Partner Abuse, 3(2), 231-280. https://doi.org/10.1891/1946-6560.3.2.231

Carlson, B. E., McNutt, L. A., Choi, D. Y., \& Rose, I. M. (2002). Intimate partner abuse and mental health the role of social support and other protective factors. Violence against Women, 8(6), 720-745. doi: https://doi.org/10.1177/10778010222183251

Courvant, D., \& Cook-Daniels, L. (2012). Trans and intersex survivors of domestic violence: Defining terms, barriers and responsibilities. Trans Survivor Project. Retrieved from http://www.vawnet.org/Assoc_Files_VAWnet/TransandIntersexSurvivors.pdf

Craft, S. M., \& Serovich, J. M. (2005). Family-of-origin factors and partner violence in the intimate relationships of gay men who are HIV positive. Journal of Interpersonal Violence, 20(7), 777-791. doi: 10.1177/0886260505277101

Cramer, D. (2003). Facilitativeness, conflict, demand for approval, self-esteem, and satisfaction with romantic relationships. Journal of Psychology, 137(1), 83-98. http://dx.doi.org/10.1080/00223980309600601

Daigneault, I., Hébert, M., \& McDuff, P. (2009). Men's and women's childhood sexual abuse and victimization in adult partner relationships: A study of risk factors. Child Abuse \& Neglect, 33(9), 638-647. doi: 10.1016/j.chiabu.2009.04.003

Dececco, J.P., Letellier, P., \& Island, D. (2013). Men who beat the men who love them: Battered gay men and domestic violence. Routledge, UK: Taylor \& Francis.

Edwards, K. M., Sylaska, K. M., \& Neal, A. M. (2015). Intimate partner violence among sexual minority populations: A critical review of the literature and agenda for future research. Psychology of Violence, 5(2), 112-121. doi: 10.1037/a0038656 
Farrington, D. P., Ttofi, M. M., \& Piquero, A. R. (2016). Risk, promotive, and protective factors in youth offending: Results from the Cambridge study in delinquent development. Journal of Criminal Justice, 45, 63-70. http://dx.doi.org/10.1016/j.jcrimjus.2016.02.014

Fortunata, B., \& Kohn, C. S. (2003). Demographic, psychosocial, and personality characteristics of lesbian batterers. Violence \& Victims, 18, 557-568. http://dx.doi.org/10.1891/vivi.2003.18.5.557

Glass, N., Koziol-McLain, J., Campbell, J., \& Block, C. (2004). Female- perpetrated femicide and attempted femicide: A case series. Violence against Women, 10(6), 606625.

Gondolf, E. W., Fisher, W. W., Fisher, E., \& McPherson, J. R. (1988). Racial differences among shelter residents: A comparison of Anglo, Black, and Hispanic battered. Journal of Family Violence, 3(1), 39-51. doi:10.1007/BF00994665

Hamel, J. (2006). Domestic violence: A gender-inclusive conception. In J. Hamel, \& T. Nicholls (Eds.), Family interventions in domestic violence: A handbook of genderinclusive theory and treatment (pp. 3-26). New York, NY: Springer Publishing.

Hendrick, S. S. (1988). A generic measure of relationship satisfaction. Journal of Marriage and the Family, 50(1), 93-98.

Hequembourg, A. L., Parks, K. A., \& Vetter, C. (2008). Sexual identity and gender differences in substance use and violence: An exploratory study. Journal of LGBT issues in counseling, 2(3), 174-198. http://dx.doi.org/10.1080/15538600802119301

Houston, E., \& McKirnan, D. J. (2007). Intimate partner abuse among gay and bisexual men: Risk correlates and health outcomes. Journal of urban health : Bulletin of the New York Academy of Medicine, 84(5), 681-690. doi:10.1007/s11524-007-9188-0

Ireland, J.L., \& Birch, P. (2013). Emotionally abusive behaviour in young couples: 
Exploring a role for implicit aggression. Victims \& Violence, 28(4), 656-69. doi: 10.1891/0886-6708.VV-D-12-00021

Kelly, C. E., \& Warshafsky, L. (1997). Partner abuse in gay male and lesbian couples. Paper presented at the Third National Conference of Family Violence Researchers, Durham, NH.

Landolt, M. A., \& Dutton, D. G. (1997). Power and personality: An analysis of gay male intimate abuse. Sex Roles 37(5), 335-359. doi:10.1023/A:1025649306193

Lang, A.J., \& Stein, M.B. (2005). An abbreviated PTSD checklist for use as a screening instrument in primary care. Behaviour Research and Therapy, 43(5), 585-594. doi: 10.1016/j.brat.2004.04.005

Leventhal, B., \& Lundy, S.E. (Eds.). (1999). Same-sex domestic violence: Strategies for change. Thousand Oaks, CA: Sage.

Murphy, C. M., \& Hoover, S. A. (1999). Measuring emotional abuse in dating relationships as a multifactorial construct. Violence \& Victims, 14(1), 39-53.

O’Leary, K. D., \& Maiuro, R. D. (Eds.). (2001). Psychological abuse in violent domestic relations. New York, NY: Springer Publishing.

Hamel, J., \& Nicholls, T. L. (2006). Family interventions in domestic violence: A handbook of gender-inclusive theory and treatment. New York: Springer Publishing Co.

Ireland, J. L. (2011). Violence assessment and intervention. In G. Davey (Ed.), Applied psychology (pp. 291 - 316), BPS, UK: Wiley-Blackwell.

Nowinski, S. N., \& Bowen, E. (2012). Partner violence against heterosexual and gay men: Prevalence and correlates. Aggression and Violent Behavior, 17(1), 36-52. http://dx.doi.org/10.1016/j.avb.2011.09.005

Nieves-Rosa, L. E., Carballo-Diéguez, A., \& Dolezal, C. (2000). Domestic abuse and HIV- 
risk behavior in Latin American men who have sex with men in New York City. Journal of Gay \& Lesbian Social Services, 11(1), 77-90. doi: 10.1300/J041v11n01_04

O’Keefe, M. (1997). Predictors of dating violence among high school students. Journal of Interpersonal Violence 12, 546-568.

Outlaw, M. (2009). No one type of intimate partner abuse: Exploring physical and nonphysical abuse among intimate partners. Journal of Family Violence, 24, 263-272. doi: 10.1007/s10896-009-9228-5

Papazian, N., \& Ball, M. (2016). Intimate-partner violence within the Queensland transgender community: Barriers to accessing services and seeking help. In M. Ball., T. Crofts \& A. Dwyer (Eds.), Queering Criminology (pp. 229-247). UK: Palgrave Macmillan.

Rosen, L. N., Parmley, A. M., Knudson, K. H., \& Fancher, P. (2002). Intimate partner violence among married male U.S Army soldiers: Ethnicity as a factor in self-reported perpetration and victimization. Violence \& Victims, 17(5), 607-622. doi:10.1016/j.cpr.2005.05.009

Salom, C. L., Williams, G. M., Najman, J. M., \& Alati, R. (2015). Substance use and mental health disorders are linked to different forms of intimate partner violence victimisation. Drug and Alcohol Dependence, 151, 121-127. http://dx.doi.org/10.1016/j.drugalcdep.2015.03.011

Smith, B. W, Dalen, J., Wiggins, K., Tooley, E., Christopher, P., \& Bernard, J (2008). The Brief Resilience Scale: Assessing the ability to bounce back. International Journal of Behavioral Medicine, 15(3), 194-200. doi: 10.1080/10705500802222972

Stith, S.M., Green, N.M., Smith, D.B., \& Ward, D.B. (2008). Marital satisfaction and discord as risk markers for intimate partner violence: A meta-analytical review. Journal of Family Violence, 23(3), 149-160. doi: 10.1007/s10896-007-9137-4 
Testa, M., \& Leonard, K. E. (2001). The impact of marital aggression on women's psychological and marital functioning in a newlywed sample. Journal of Family Violence, 16(2), 115-130. doi: 10.1023/A:1011154818394

Turell, S., Herrmann, M., Hollander, G., \& Galletly, C. (2012). Lesbian, Gay, Bisexual, and Transgender communities’ readiness for intimate partner violence prevention. Journal of Gay \& Lesbian Social Services, 24(3), 289-310. doi:

$10.1080 / 10538720.2012 .697797$

Turell, S. C. (2000). A descriptive analysis of same-sex relationship violence for a diverse sample. Journal of Family Violence, 15(3), 281-293. doi: 10.1023/A:1007505619577

Weiss, K. (2015). The role of relationship therapy in working with family violence. InPsych: The bulletin of the Australian Psychological Society Ltd, 37(5), 14.

Zigmond A.S., \& Snaith R.P. (1983). The Hospital Anxiety and Depression Scale. Acta Psychiatr Scand, 67(6), 361-70. doi: 10.1111/j.1600-0447.1983.tb09716.x

Footnote

${ }^{1}$ Space restraints do not allow all items to be outlined but a table of results is available from the corresponding author on request. 
Table 1. Factor loadings on amended MMEA for victimisation and perpetration including scale reliabilities and means.

\begin{tabular}{|c|c|}
\hline MMEA item - Victimisation & \\
\hline $\begin{array}{l}\text { Factor } 1 \text { Label/variance - Conflict orientated aggression, including threats and fear } \\
\text { inducing behaviours/49.9\%; Scale } \alpha=.95 ; \mathrm{n}=277\end{array}$ & Loading \\
\hline Stood or hovered over the other person during a conflict or disagreement & .99 \\
\hline Pushed the other person during a conflict or disagreement & .89 \\
\hline Drove recklessly to frighten the other person & .85 \\
\hline Hit or kicked the other person during a conflict or disagreement & .82 \\
\hline Put their face right in front of the other person's face to make a point more forcefully & .70 \\
\hline Threatened to hit the other person & .69 \\
\hline Became angry enough to frighten the other person & .66 \\
\hline Called the other person worthless & .63 \\
\hline Threw, smashed, hit, or kicked something in front of the other person & .599 \\
\hline Threatened to throw something at the other person & .592 \\
\hline Called the other person names to hurt them & .56 \\
\hline $\begin{array}{l}\text { Factor } 2 \text { Label/variance - Hostile ignorance and control of communication/7.3\%; Scale } \alpha \\
=.93 ; \mathrm{n}=284\end{array}$ & Loading \\
\hline Sulked or refused to talk about an issue with them & .87 \\
\hline Refused to acknowledge a problem that the other person thought was important & .81 \\
\hline Acted cold or distant to the other person when angry & .78 \\
\hline Became so angry that they were unable or unwilling to talk to the other person & .779 \\
\hline Said that someone else would be a better partner & .74 \\
\hline Refused to have any discussion of the problem with them & .66 \\
\hline Changed the subject on purpose when the other person was trying to discuss a problem & .59 \\
\hline Factor 3 Label/variance - Social control, suspicion and possessiveness, including threats & Loading \\
\hline
\end{tabular}




\begin{tabular}{|c|c|}
\hline to possessions/3.7\%; Scale $\alpha=.92 ; \mathrm{n}=274$ & \\
\hline Complained that the other person spends too much time with friends & -.76 \\
\hline Got angry because the other person when somewhere without telling you & -.75 \\
\hline Tried to stop the other person from seeing certain friends or family members & -.74 \\
\hline Asked the other person where they had been or who they were with in a suspicious manner & -.72 \\
\hline Threatened to hurt the other person's pet(s) & -.68 \\
\hline Secretly searched through the other person's belongings & -.67 \\
\hline Tried to make the other person feel guilty for not spending enough time together & -.61 \\
\hline $\begin{array}{l}\text { Checked up on the other person by asking friends or relatives where they were or who they } \\
\text { were with }\end{array}$ & -.58 \\
\hline Called the other person a loser, failure or similar term & -.53 \\
\hline MMEA item - Perpetration & \\
\hline $\begin{array}{l}\text { Factor } 1 \text { Label/variance - Hostile ignorance and control of communication/27.1\%; Scale } \\
\alpha=.91 ; n=284\end{array}$ & Loading \\
\hline Refused to acknowledge a problem that the other person thought was important & .796 \\
\hline Sulked or refused to talk about an issue with them & .790 \\
\hline Acted cold or distant to the other person when angry & .777 \\
\hline Refused to have any discussion of the problem with them & .774 \\
\hline Changed the subject on purpose when the other person was trying to discuss a problem & .70 \\
\hline Became so angry that they were unable or unwilling to talk to the other person & .64 \\
\hline Said that someone else would be a better partner & .58 \\
\hline $\begin{array}{l}\text { Factor } 2 \text { Label/variance - Conflict orientated aggression, including threats and fear } \\
\text { inducing behaviour/9.7\%; Scale } \alpha=.89 ; \mathrm{n}=280\end{array}$ & Loading \\
\hline Hit or kicked the other person during a conflict or disagreement & -.92 \\
\hline Became angry enough to frighten the other person & -.82 \\
\hline Stood or hovered over the other person during a conflict or disagreement & -.81 \\
\hline
\end{tabular}




\begin{tabular}{|c|c|}
\hline Drove recklessly to frighten the other person & -.79 \\
\hline Put their face right in front of the other person's face to make a point more forcefully & -.68 \\
\hline Pushed the other person during a conflict or disagreement & -.65 \\
\hline Intentionally avoided the other person during a conflict or disagreement & -.59 \\
\hline Threatened to throw something at the other person & -.57 \\
\hline Deliberately damaged the other person's property & -.55 \\
\hline $\begin{array}{l}\text { Factor } 3 \text { Label/variance }- \text { Suspicion and possessiveness, including threats to } \\
\text { possessions/4.3\%; Scale } \alpha=.74 ; \mathrm{n}=287\end{array}$ & Loading \\
\hline Asked the other person where they had been or who they were with in a suspicious manner & .71 \\
\hline Secretly searched through the other person's belongings & .64 \\
\hline Threatened to hurt the other person’s pet(s) & .57 \\
\hline Got angry because the other person when somewhere without telling you & .55 \\
\hline
\end{tabular}

NB: All items correlated positively with their respective scales. 
Table 2: Means overall and across gender and sexuality for the amended MMEA factors.

\begin{tabular}{|c|c|c|c|c|c|c|c|c|}
\hline \multirow[b]{2}{*}{ Victimisation } & \multicolumn{3}{|c|}{ Gender } & \multicolumn{4}{|c|}{ Sexuality } & \multirow[b]{2}{*}{$\begin{array}{l}\text { Other } \\
\text { M/SD (n) }\end{array}$} \\
\hline & $\begin{array}{l}\text { Overall } \\
\text { M/SD } \\
\text { (n) }\end{array}$ & $\begin{array}{l}\text { Men } \\
\text { M/SD (n) }\end{array}$ & $\begin{array}{l}\text { Women } \\
\text { M/SD (n) }\end{array}$ & $\begin{array}{l}\text { Trans } \\
\text { M/SD (n) }\end{array}$ & $\begin{array}{l}\text { Intersex } \\
\text { M/SD (n) }\end{array}$ & $\begin{array}{l}\text { Lesbian/Gay/ } \\
\text { Homosexual } \\
\text { M/SD (n) }\end{array}$ & $\begin{array}{l}\text { Bisexual } \\
\text { M/SD (n) }\end{array}$ & \\
\hline $\begin{array}{l}\text { Conflict orientated aggression, including } \\
\text { threats and fear inducing behaviour (F1) }\end{array}$ & $\begin{array}{l}3.7 / 10.1 \\
(277)\end{array}$ & $\begin{array}{l}2.7 / 7.57 \\
(94)\end{array}$ & $\begin{array}{l}4.05 / 10.9 \\
(153)\end{array}$ & $\begin{array}{l}6.9 / 16.2 \\
(19)\end{array}$ & $\begin{array}{l}.85 / 2.26 \\
(7)\end{array}$ & $\begin{array}{l}3.7 / 10.2 \\
(232)\end{array}$ & $\begin{array}{l}2.6 / 5.77 \\
(25)\end{array}$ & $\begin{array}{l}5.3 / 14.4 \\
(19)\end{array}$ \\
\hline Hostile ignorance and control of & $10.1 / 10.5$ & $9.9 / 10.0$ & $10.3 / 10.6$ & $10.0 / 12.4$ & $9.8 / 13.5$ & $9.9 / 10.4$ & $11.6 / 12.5$ & 9.9/9.5 \\
\hline communication (F2) & $(284)$ & $(98)$ & $(156)$ & (19) & (7) & (238) & $(25)$ & $(20)$ \\
\hline Social control and possessiveness, & $6.8 / 10.3$ & $6.8 / 8.7$ & $6.5 / 11.1$ & $9.4 / 13$ & $8.3 / 8.1$ & $6.7 / 10.3$ & $7.3 / 11.1$ & $6.1 / 10.6$ \\
\hline including threats to possessions (F3) & $(274)$ & $(92)$ & $(152)$ & (19) & (7) & $(228)$ & $(25)$ & (19) \\
\hline \multicolumn{9}{|l|}{ Perpetration } \\
\hline Hostile ignorance and control of & $8.8 / 8.6$ & $7.8 / 7.3$ & $9.3 / 9.2$ & $8.0 / 8.1$ & $11.6 / 12.3$ & $8.6 / 8.3$ & $9.6 / 10.5$ & $10.4 / 9.2$ \\
\hline communication (F1) & $(284)$ & $(97)$ & $(157)$ & (19) & (7) & (238) & (25) & (20) \\
\hline Conflict orientated aggression, including & $2.7 / 5.9$ & $2.2 / 4.6$ & $3.0 / 6.8$ & $3.3 / 4.9$ & $1.0 / 1.3$ & $2.7 / 6.0$ & $3.9 / 6.6$ & $1.3 / 1.9$ \\
\hline threats and fear inducing behaviour (F2) & $(280)$ & (96) & $(155)$ & $(18)$ & (7) & $(235)$ & (24) & (19) \\
\hline Suspicion and possessiveness, including & 3.3/3.9 & $4.3 / 4.6$ & $2.8 / 3.5$ & $1.9 / 2.2$ & $3.6 / 2.2$ & $3.4 / 3.8$ & $2.6 / 3.9$ & $3.3 / 4.9$ \\
\hline threats to possessions (F3) & (287) & $(97)$ & $(160)$ & (19) & (7) & $(240)$ & (25) & (20) \\
\hline
\end{tabular}


Table 3. Joint Factor Analysis with HADS and PCL-C: Factor loadings, scale reliabilities and means.

\begin{tabular}{|c|c|}
\hline $\begin{array}{l}\text { Factor } 1 \text { Label/variance - Anxiety and Hyper-arousal/45.4\% } \\
\text { Scale } \alpha=.90 ; n=260 ; \text { M 9.65; SD } 9.6\end{array}$ & \\
\hline Item (measure) & Loading \\
\hline Worrying thoughts go through my mind (HAD) & .83 \\
\hline I get sudden feelings of panic (HAD) & 64 \\
\hline I feel tense or wound up (HAD) & .635 \\
\hline Bothered by feeling jumpy or easily startled (PCL-C) & .634 \\
\hline I can[not] sit at ease and feel relaxed (HAD) & 631 \\
\hline I get sort of frightened feeling as it something awful is about to happen (HAD) & .62 \\
\hline Bothered by being super-alert or watchful or on guard (PCL-C) & .60 \\
\hline Having difficulty concentrating (PCL-C) & .58 \\
\hline Feeling irritable or having angry outbursts (PCL-C) & .50 \\
\hline $\begin{array}{l}\text { Factor } 2 \text { Label/variance - Loss of enjoyment and interest/6.32\% } \\
\text { Scale } \alpha=.88 ; \mathrm{n}=268 ; \mathrm{M} 2.85 ; \mathrm{SD} 3.40\end{array}$ & Loading \\
\hline I [hardly] look forward with enjoyment to things (HAD) & .79 \\
\hline I [hardly] enjoy the things I used to enjoy (HAD) & .73 \\
\hline I can[not] laugh and see the funny side of things [HAD] & 638 \\
\hline Bothered by a loss of interest in activities you used to enjoy [PCL-C] & .636 \\
\hline I [do not] feel cheerful [HAD] & .53 \\
\hline $\begin{array}{l}\text { Factor } 3 \text { Label/variance - Intrusion of stressful events into awareness and attempts to } \\
\text { avoid the same/3.0\% } \\
\text { Scale } \alpha=.91 ; \mathrm{n}=245 ; \mathrm{M} 6.68 ; \mathrm{SD} 7.01\end{array}$ & Loading \\
\hline $\begin{array}{l}\text { Bothered by feeling very upset when something reminded you of a stressful experience from } \\
\text { the past (PCL-C) }\end{array}$ & .80 \\
\hline Bothered by avoiding thinking about or talking about a stressful experience from th & .78 \\
\hline
\end{tabular}




\begin{tabular}{|l|l|}
\hline having feelings related to it (PCL-C) & \\
\hline Bothered by having physical reactions (e.g. heart pounding, trouble breathing, sweating) when & .77 \\
\hline Bothered by avoiding activities or situations because they reminded you of a stressful & .74 \\
\hline $\begin{array}{l}\text { Bothered by repeated, disturbing memories, thoughts or images of a stressful experience form } \\
\text { the past (PCL-C) }\end{array}$ & .68 \\
\hline $\begin{array}{l}\text { Bothered by suddenly acting or feeling as if a stressful experience were happening again (as if } \\
\text { you were relieving it) (PCL-C) }\end{array}$ & .65 \\
\hline Bothered by repeated, disturbing dreams of a stressful experience from the past (PCL-C) & .60 \\
\hline
\end{tabular}

NB: All items correlated positively with their respective scales. 

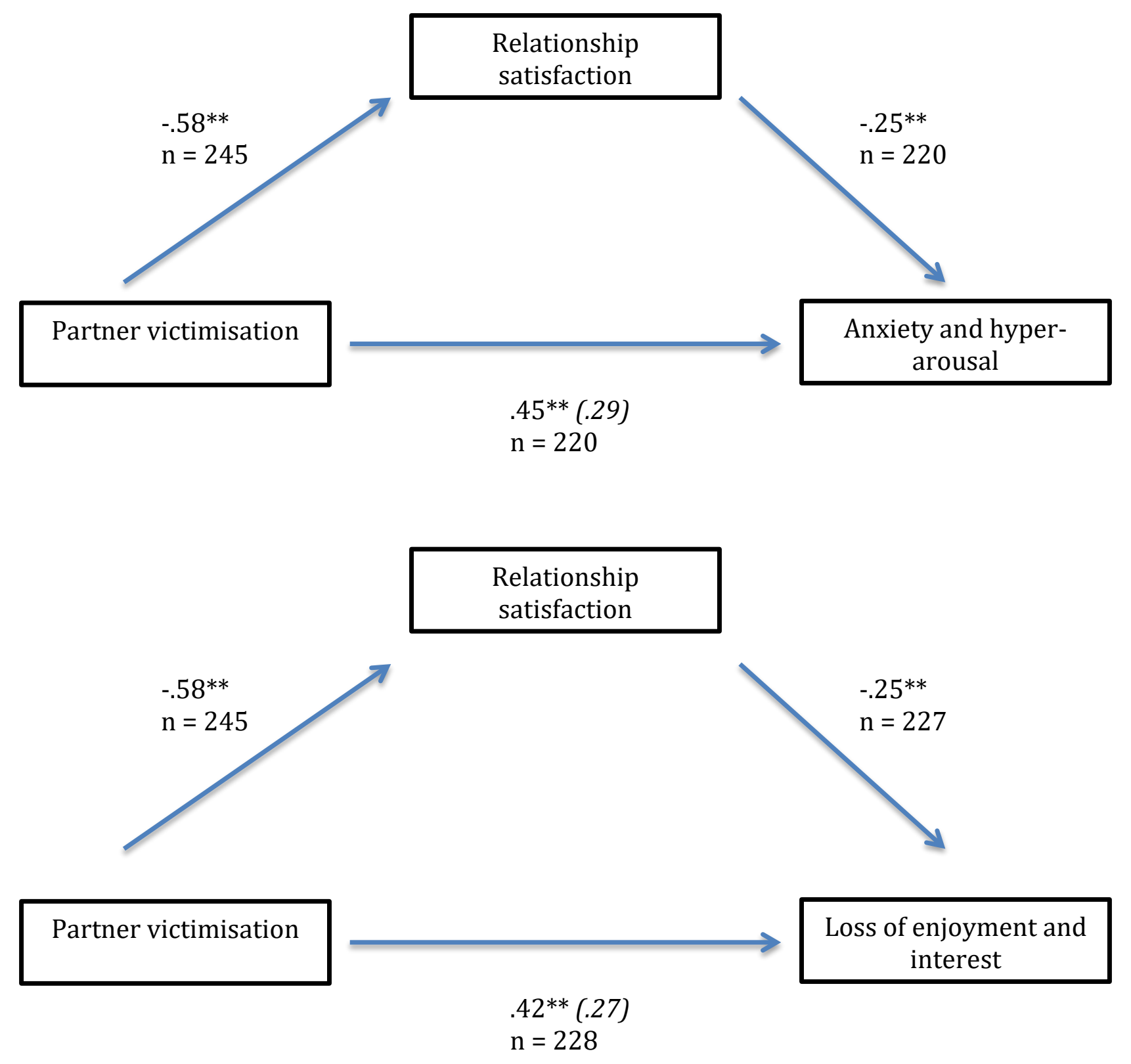

Figure 1: Standardised regression coefficients for the relationship between total partner victimisation and emotional distress in the form of anxiety and hyper-arousal and loss of enjoyment and interest as mediated by a decreased perception of relationship satisfaction. The standardized regression coefficient between victimisation and each component of emotional distress, controlling for relationship satisfaction, is in parentheses. $p<.001^{* *}$. 

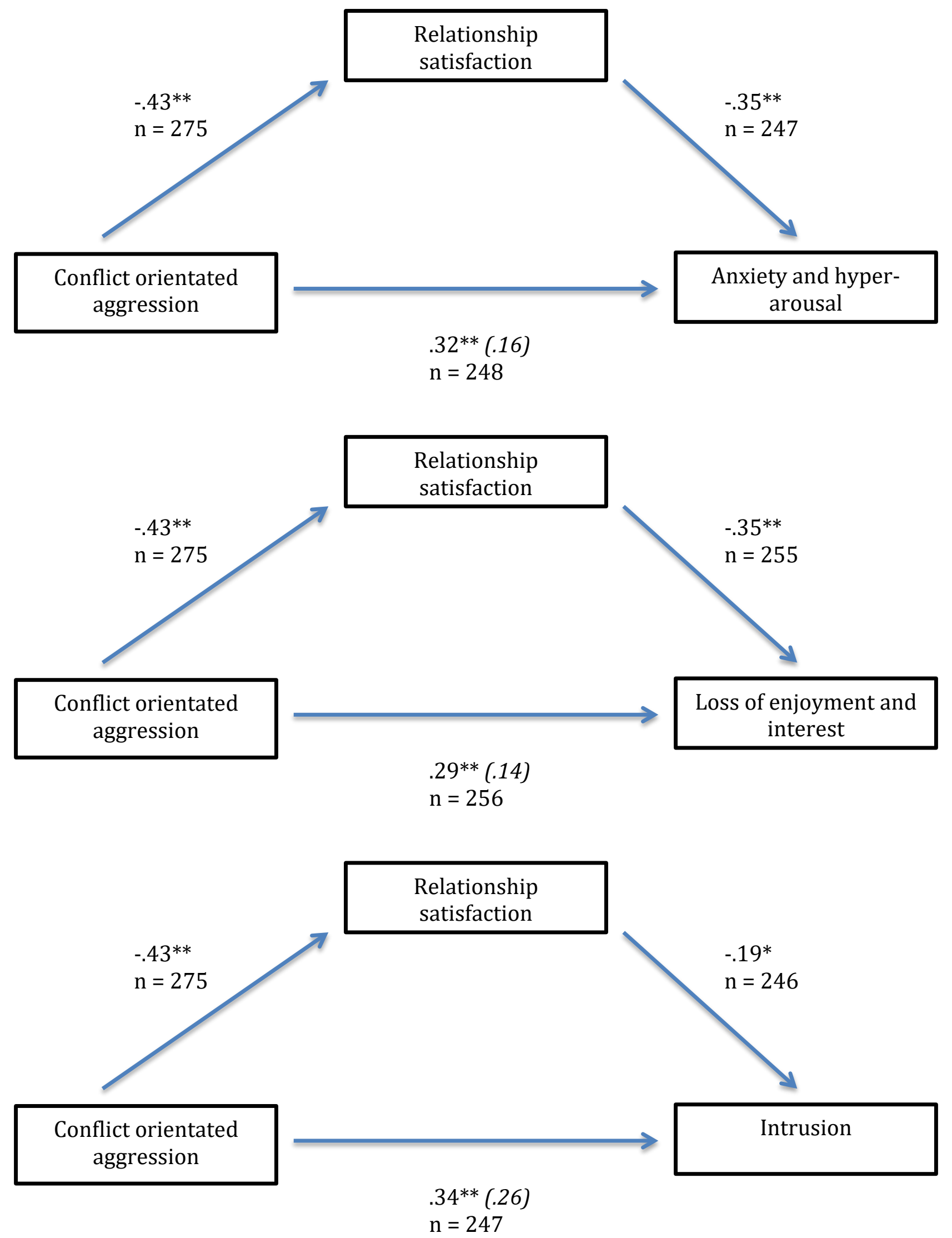

Figure 2: Standardised regression coefficients for the relationship between conflict orientated partner aggression and emotional distress as mediated by a decreased perception of relationship satisfaction. The standardized regression coefficient between victimisation and each component of emotional distress, controlling for relationship satisfaction, is in parentheses. $p<.05^{*} . p<.001^{* *}$. 

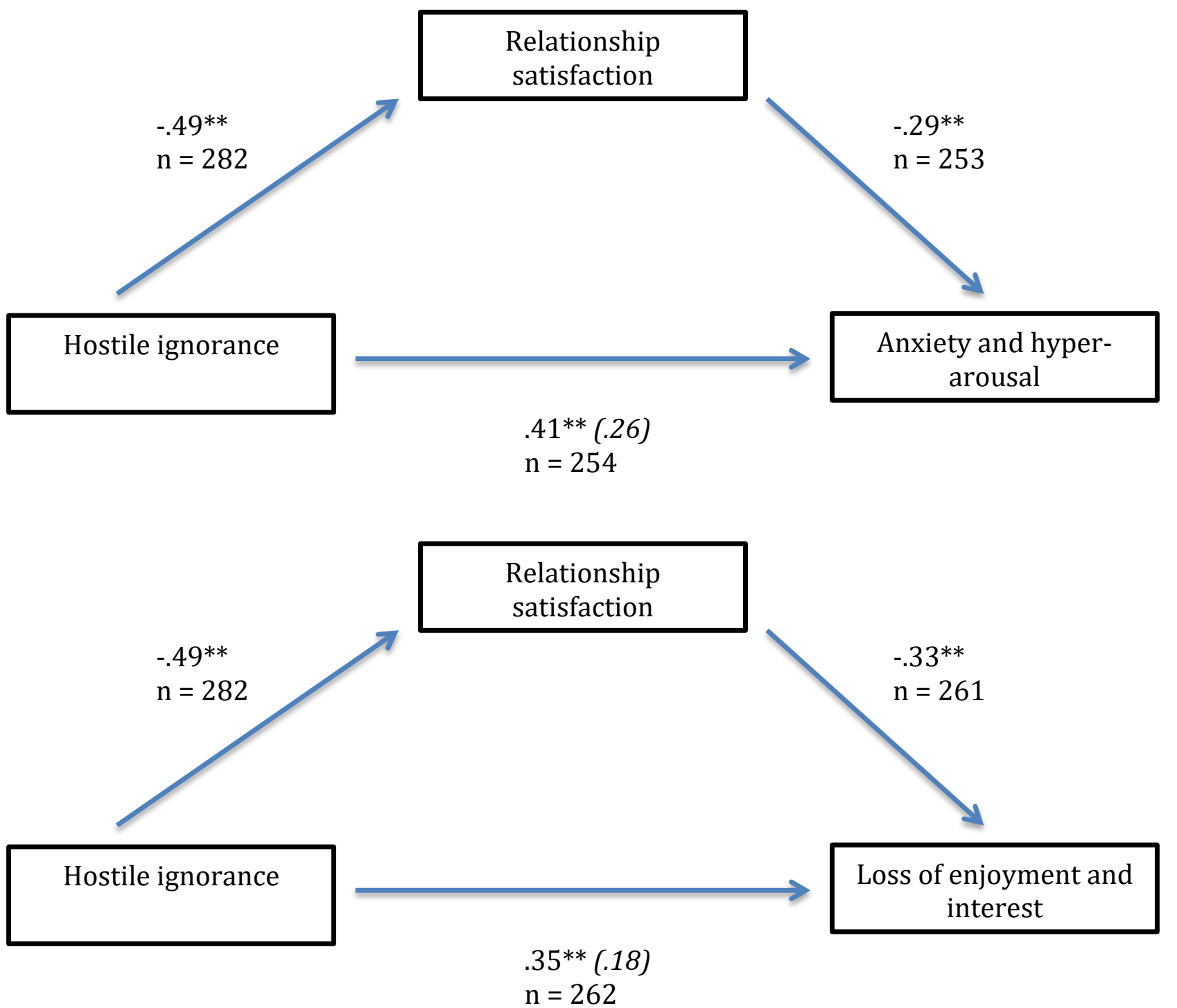

$. p<.001^{*}$.

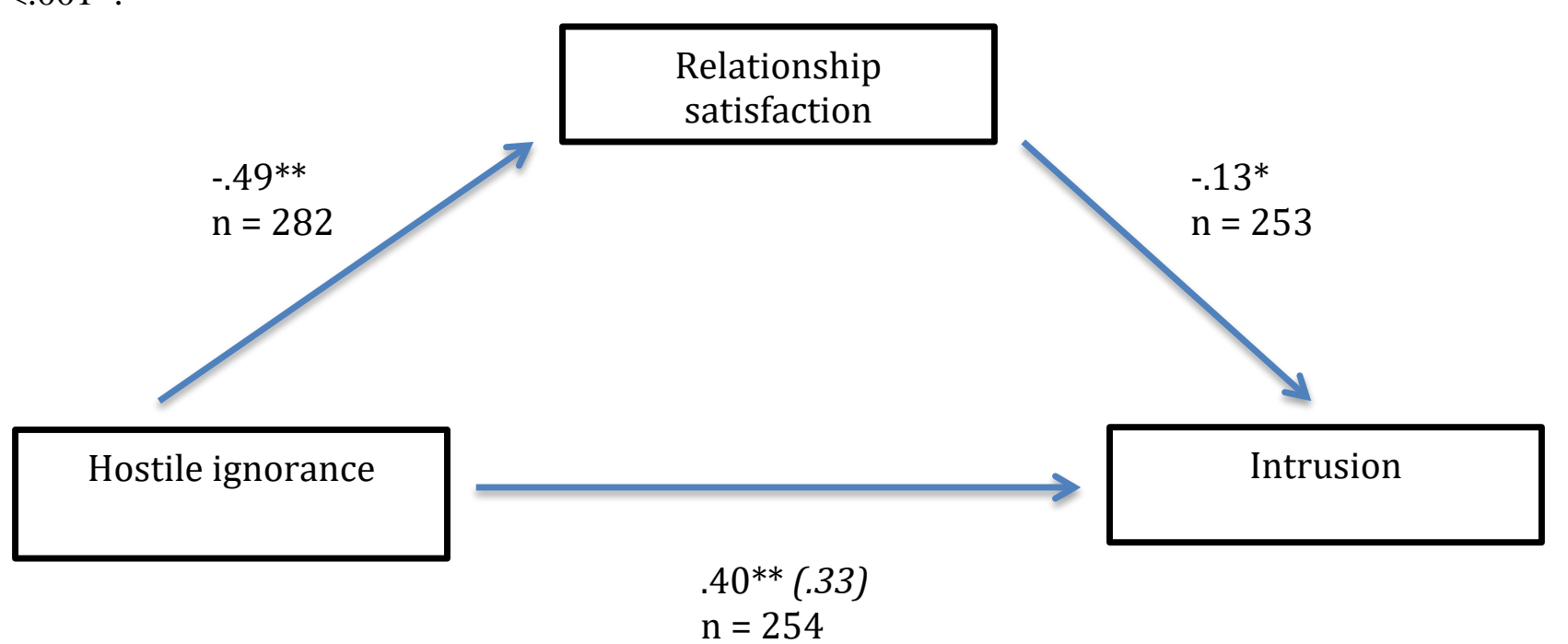

Figure 3: Standardised regression coefficients for the relationship between hostile ignorance and control of communication and emotional distress as mediated by a decreased perception of relationship satisfaction. The standardized regression coefficient between victimisation and each component of emotional distress, controlling for relationship satisfaction, is in parentheses. $p<.05^{*} . p<.001^{* *}$. 

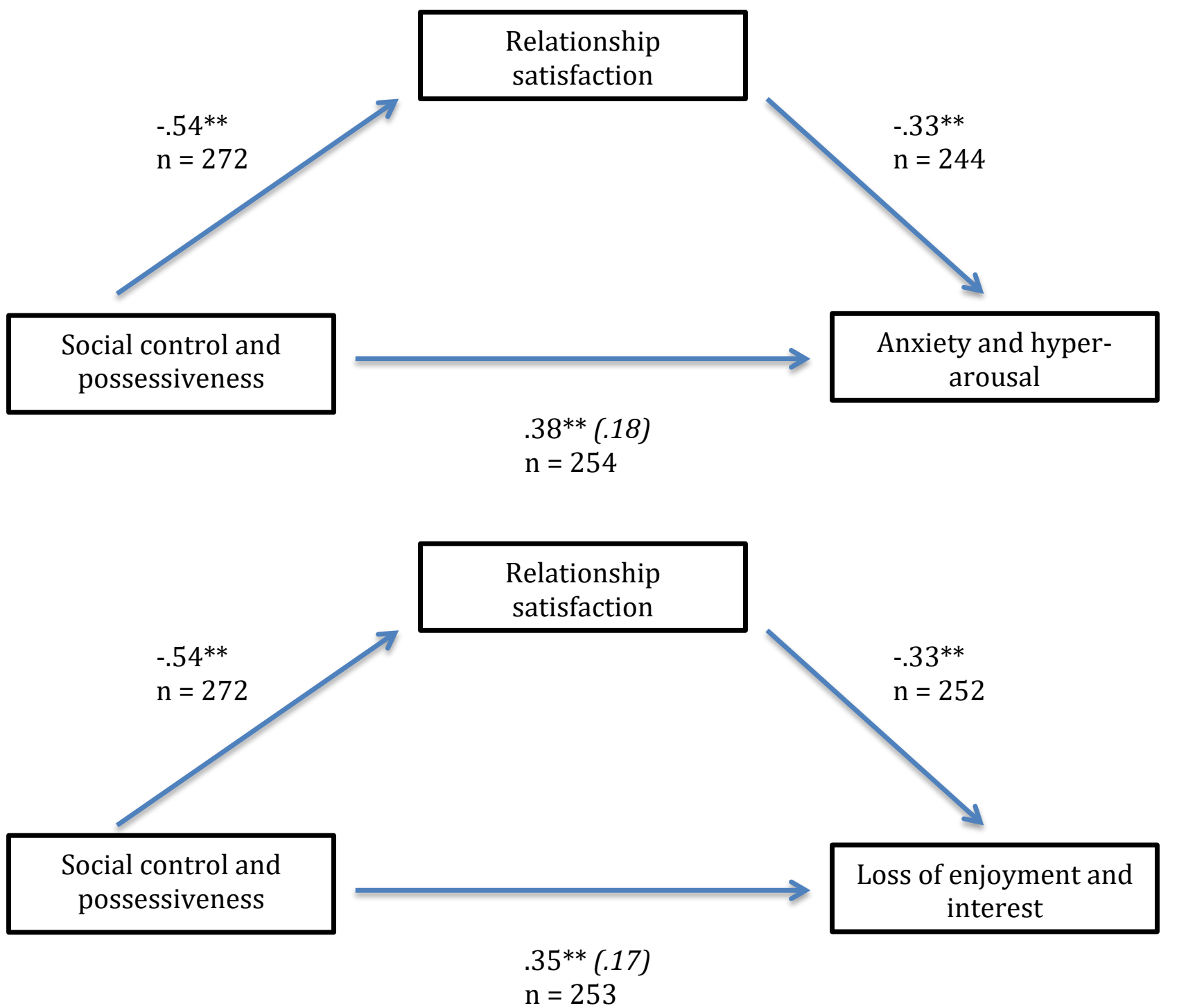

$. p<.001^{*}$.

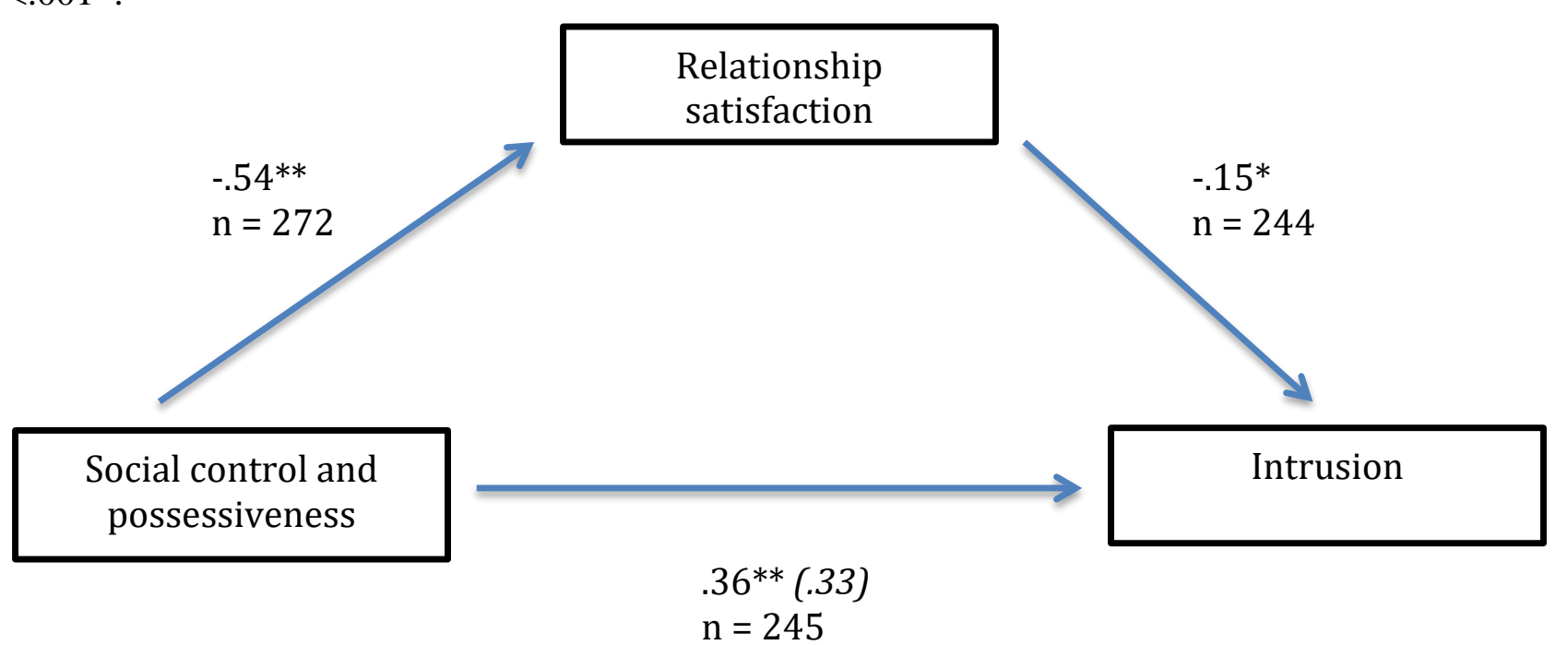

Figure 4: Standardised regression coefficients for the relationship between social control and possessiveness and emotional distress as mediated by a decreased perception of relationship satisfaction. The standardized regression coefficient between victimisation and each component of emotional distress, controlling for relationship satisfaction, is in parentheses. $p<.03^{*} . p<.001^{* *}$. 